\title{
Aleida García Aguirre (2015), La revolución que llegaría. Experiencias de solidaridad $y$ redes de maestros y normalistas en el movimiento campesino y la guerrilla moderna en Chihuahua, 1960-1968, Colectivo Memorias Subalternas, México, 2015
}

\author{
Carlos Escalante Fernández \\ El Colegio Mexiquense, A. C. \\ cescalante@cma.edu.mx
}

El libro La revolución que llegaría. Experiencias de solidaridad y redes de maestros y normalistas en el movimiento campesino y la guerrilla moderna en Chihuahua, 1960-1968 de Aleida García Aguirre es un libro oportuno y bienvenido en el medio académico.

En el libro, la autora, historiadora desde abajo, militante de la esperanza e hija de una ex normalista, estudia "la participación solidaria de maestros y normalistas en la articulación y desarrollo del movimiento campesino en Chihuahua en la primera mitad de los años sesenta, y las dos guerrillas rurales que operaron en la misma entidad federativa en 1964-1965 y 1967-1968" y se propone "analizar las peculiaridades que la presencia de estos dos grupos sociales vinculados a la educación pudo otorgar a las demandas campesinas legales e ilegales, así como a la formulación de una crítica radical del ordenamiento económico, social y político mexicano" (2015: 23).

La historiografía mexicana sobre el magisterio es amplia y aborda diversas facetas del mundo de maestros. Condiciones de trabajo, conformación de identidades docentes, movimientos sindicales y formas organizativas, biografías, instituciones formadoras de maestros, obras pedagógicas, saberes magisteriales y docentes, papeles ejercidos por el magisterio en procesos de intermediación cultural y procesos de feminización magisterial son algunos de los grandes temas estudiados en diferentes épocas de la historia y en diversas regiones del país. Ha conformado un sólido corpus de conocimiento que permite comprender a este importante gremio y a entender los procesos educativos. 
La revolución que llegaría versa, en palabras de la autora "sobre la peculiaridad que la participación de normalistas y maestros, constituidos como un gremio reticular, otorgó a la conformación de un sujeto político, en este caso al movimiento campesino, el Grupo Popular Guerrillero y su sucesor el Grupo Popular Guerrillero Arturo Gámiz" (2015: 26).

El libro de Aleida García Aguirre hace confluir dos campos temáticos de conocimiento: la historiografía de la educación y el emergente estudio de los movimientos guerrilleros en México en el siglo Xx. Una primera impresión de la lectura establece que el libro sólo adiciona conocimiento al ya acumulado en estas historiografías. No es así para el caso de la historiografía educativa porque la autora ofrece un conjunto de cuestiones que vislumbran nuevos acercamientos a la comprensión del magisterio, que una nueva generación de historiadoras jóvenes ha emprendido en años recientes, generación a la que hay que seguir leyendo y apoyando en su formación.

Entre las cuestiones más sobresalientes que ofrece el libro, se pueden destacar cinco:

La primera, reconoce que son pocos los acercamientos que estudian a maestros en formas de participación que no conciernen a su trabajo docente, pero que reflejan la manera en que conciben la participación política, social y cultural.

Si bien en algunas biografías o memorias de maestros se pueden advertir algunas facetas de este tipo de participación, por lo general los estudios históricos sobre el magisterio no ponen especial interés en estas formas participativas, voluntarias y comprometidas que no son, insisto, ni concernientes a su trabajo como profesores ni propias de gremio en lucha por demandas propias. En algunos trabajos sobre el período de la revolución y el posrevolucionario (1910-1940) se ha advertido el papel que los maestros rurales tuvieron en los procesos de reparto agrario de sus comunidades. Por lo general, se ha explicado como parte de una política que les asignaba ese papel, esto es, como parte de sus actividades que debían desarrollar al ser profesores rurales. Si bien se trata de esfuerzos intelectuales muy valiosos, poco ayudan a entender las prácticas políticas comprometidas que los grupos de maestros han tenido en la historia social de México. ¿Cómo se establecen esas convicciones, que llevan incluso a arriesgar la vida de quiénes las asumen en aras de la defensa de ideales sobre mejoras sociales y políticas de los sectores populares?, ¿qué circunstancias propician los acercamientos orgánicos entre un sector popular (obreros, campesinos, indígenas, mujeres, mineros, etc.) y un grupo de profesores y estudiantes normalistas?, ¿en qué contextos e instituciones se forma este tipo de conciencia política? Poco sabemos al respecto.

Por lo tanto, acercarse al estudio histórico de un grupo de maestros y de estudiantes normalistas en relación política con cuestiones ajenas a las instituciones educativas, en este caso, la participación en el movimiento campesino y en el accionar guerrillero constituye una novedad significativa. En ese sentido, las preguntas de Aleida Aguirre resultan muy pertinentes: "¿por qué algunos sujetos pertenecientes a un gremio que se debía al estado decidieron erigir 
organizaciones políticas armadas que pretendían la desarticulación del ordenamiento económico imperante y del estado mismo?" y "¿cómo pudieron transfigurarse en intelectuales contrahegemónicos?" (2015: 24).

Segunda, el tema no es lo único novedoso en este libro. También el acercamiento historiográfico a una época que vivimos más de uno de los que nos dedicamos a la investigación histórica de la educación. Quizá por esa circunstancia nos parece que aún no es oportuno historiarla: la década de los sesenta. Son pocos los estudios educativos que desde la historia se han hecho al respecto. Por supuesto, la gran excepción es la amplia bibliografía sobre el movimiento estudiantil popular de 1968, su amplitud es explicable por la importancia política del movimiento y su trascendencia en el país.

A partir de ahora, no deberá extrañarnos la proliferación de estudios sobre la educación que se hagan sobre estos años, ya que se trata de un período muy importante de la educación del país. En algunos casos, constituye un período base como, por citar sólo un ejemplo, el uso cotidiano y sistemático de los libros de texto gratuito en la educación primaria, tema del cual también ya comienzan a aparecer investigaciones del período. El libro de Aleida García Aguirre constituye uno de los primeros trabajos en ese sentido y despertará inquietudes sobre el tema y el período que enriquecerán nuestra historiografía.

Tercera, hay, además de lo anterior, una actitud investigativa fresca, e igualmente novedosa, que también debe ser valorada. La autora deja explícito sus compromisos éticos y políticos y a la vez se exige rigurosidad en la investigación. Nos recuerda que el academicismo libre de compromisos políticos no es la única opción para realizar investigación sociohistórica, sino que se puede trabajar con seriedad un tema sin renunciar a las convicciones políticas propias de la autora en tanto ciudadana y profesionista. A 50 años del asalto al cuartel Madera, y con el contexto inmediato de la desaparición de los 43 estudiantes normalistas de Ayotzinapa y el asesinato de varios de ellos ocurridos en Iguala, Guerrero en septiembre de 2014, se edita este libro auspiciado por el colectivo Memorias subalternas del que la autora es integrante.

Para ella "toda historiografía contiene una posición política: algunas son transparentes, otras cifran sus filiaciones y fobias." "Soy partidaria -agrega- de mostrar al lector el lugar desde donde se escribe, y al mismo tiempo me inclino por no convertir a la historiografía en el estrado tras el cual se pronuncian las disertaciones políticas." Y concluye con claridad su postura señalando que "el autor puede hacer de su obra una contribución que argumente a favor de su militancia política, pero es una falta de respeto al lector y a la profesión deteriorar la calidad de la investigación y la argumentación histórica para privilegiar las acusaciones y las apologías; es otra falta de respeto, por no hablar de lo aburrido que resulta, dictar cátedra política en lugar de problematizar la posición política" (2015: 232). 
Esta postura se muestra de manera coherente en la investigación que contiene el libro, en el cual la simpatía de la autora por los protagonistas de su historia no le impide hacer un análisis histórico riguroso en el que ha procurado cuidar su subjetividad. No es éste un asunto menor, por lo que me parece importante resaltarlo.

La cuarta cuestión, relacionada con el análisis histórico que realiza la autora para dar cuenta de las experiencias de solidaridad y las redes de maestros y normalistas que les permitieron vincularse con el movimiento campesino y la guerrilla chihuahuense en la década de 1960 se sustenta en un uso renovador de varios conceptos provenientes de algunos autores marxistas, Antonio Gramsci y E. P. Thompson y de Ranajit Guha del grupo de los Subaltern Studies principalmente. Así los conceptos conciencia política, clase social, intelectual orgánico, solidaridad, experiencia, entre otros, guían la investigación. La autora los muestra fecundos para explicar su problema de investigación y responder a las interrogantes que se formuló.

Obviamente Aleida García Aguirre no es la primera historiadora que intenta abrevar de la reflexión de estos autores, pero su forma de debatir con ellos, de construir referentes frente a la información recabada y su habilidad para dotar los conceptos de capacidad explicativa resultan no sólo sugerentes sino que también abren miradas revitalizadas para la historiografía de la educación. La autora sustenta su argumentación en esta construcción teórica que le permite el análisis de la participación política de los normalistas y profesores en el movimiento campesino y en la guerrilla. No existen en sus explicaciones determinismos de clase, ni de género ni de otro tipo, al contrario, una apuesta por encontrar múltiples determinaciones a la formación de conciencia política de estos profesores y estudiantes normalistas. En ese camino, la autora no se limita a encontrar la racionalidad de las decisiones políticas de los actores, ya que explora otras expresiones que hicieron a estos estudiantes normalistas y profesores comprometerse políticamente y enfrentar al poder del Estado. La autora invita a explorar las dimensiones afectivas de las decisiones políticas, una cuestión que abre un campo desconocido para estudiar los movimientos sociales.

La participación política de los actores también es explicada por la autora a partir de la descripción detallada y analítica que hace de la red social de los profesores estudiados en la IV Zona Escolar Federal de Chihuahua. Para Aleida, esta red tuvo diferentes vínculos (afectivos, políticos, familiares e institucionales) que permitieron una movilización que constituyó experiencias formativas para los profesores. Asimismo, fueron aportes útiles para los campesinos demandantes de tierra y para los grupos guerrilleros y permitieron enfrentar a grupos económicos poderosos que poseían bosques y tierras en la región de estudio y a las autoridades políticas de diverso rango y de comportamientos caciquiles.

Como toda buena investigación, este libro abre nuevas preguntas y nuevos temas de estudio. La autora menciona uno en sus conclusiones, el cual resulta muy relevante: "desentrañar 
si una posición política contestataria incide en el ejercicio y cuestionamiento de las teorías del aprendizaje" (2015: 222). Investigar sobre el vínculo entre compromiso político y quehacer pedagógico exhibe las formas pedagógicas que los movimientos magisteriales han construido y llena de contenido la consigna magisterial gritada en las calles mexicanas por profesores, "El maestro luchando, también está enseñando".

Finalmente, la lectura del libro nos permite valorar el diverso uso de fuentes de información. La autora recurre a una importante hemerografía, testimonios escritos de la época y entrevistas orales con protagonistas de la época realizadas por ella y por investigadores anteriores (como las realizadas por Carlos Montemayor). Igualmente consulta expedientes agrarios custodiados en el Registro Agrario Nacional. También valora las resoluciones que se tomaron en el II Encuentro de la Sierra que constituyen la fundamentación ideológica que sustenta a los guerrilleros estudiados por la autora.

Una cualidad del trabajo es que Aleida consigue un refinado entrecruce de las fuentes, a partir de tener muy claro el tratamiento diferente que cada tipo de fuente debe tener. El entrecruce proporciona al lector información precisa y le permite ver las dificultades que enfrenta el historiador en temas que suponen procesos de secrecía por la clandestinidad de las actividades desarrolladas por los protagonistas (luchas por la tierra, pero sobre todo apoyo solidario a los grupos guerrilleros).

Por las razones enumeradas, y por muchas otras que el lector podrá encontrar como resultado de su propia lectura, el libro de Aleida García Aguirre ocupará un lugar importante en los próximos años pues constituye una investigación comprometida, seria, rigurosa, respetuosa con los protagonistas de su historia, investigación que aborda el tema de vigencia política: ¿cómo hacer para que nuestro país transite a una sociedad justa en la que el magisterio democrático cumplirá un importante papel en su quehacer institucional pero también como grupo comprometido con causas populares? Algunas respuestas posibles pueden formularse tras la lectura de este libro. 